\title{
COMPARATIVE STUDY OF SEROMA FORMATION IN HARMONIC SCALPEL VERSUS ELECTROCAUTERY IN POST MODIFIED RADICAL MASTECTOMY
}

\author{
Muhammad Farooq Shahid, Taseer Ibrahim*, Muhammad Ali Muazzam, Hummaira Chaudhry, Usman Shah Bukhari, Ghufran Ahmed \\ Combined Military Hospital Quetta/National University of Medical Sciences (NUMS) Pakistan, *Mega Medical Hospital, Rawalpindi Pakistan
}

\section{ABSTRACT}

Objective: To compare the frequency of seroma formation in harmonic scalpel vsunipolar electrocautery in post modified radical mastectomy (MRM).

Study Design: Quasi experimental study.

Place and Duration of Study: General Surgery Department, Pak Emirates Military Hospital Rawalpindi, from Jul to Dec 2017. Methodology: Eighty women with breast carcinoma planned for modified radical mastectomy were included in the study with inclusion and exclusion criteria and divided in equal group A (Harmonic) and group B (Unipolar cautery). Randomization was performed by lottery method for both groups. A standard level III clearance was performed. All patients were followed up on weekly basis and seroma formation was evaluated in both groups.

Results: Mean age in group A and B was $51.36 \pm 11.04$ years vs $52 \pm 11.19$ years $(p>0.05)$. Mean duration of complain in group $A$ and $B$ was $1.675 \pm 0.47$ months vs $1.775 \pm 0.42(p>0.05)$. Mean time of procedure in group A and B was $110.00 \pm 4.71$ mins vs $100.875 \pm 5.14(p>0.05)$. Mean body mass index in group A and B was $30.217 \pm 4.99 \mathrm{~kg} / \mathrm{m}^{2}$ vs $30.210 \pm 5.31 \mathrm{~kg} / \mathrm{m}^{2}(p>0.05)$. Seroma formation in group A and group B patients were found to be $5(12.5 \%)$ vs $10(25 \%)$ with $(p>0.05)$.

Conclusion: Frequency of seroma formation in harmonic scalpel is lower than electrocautery in post modified radical mastectomy, so it can be safely performed along with harmonic scalpel with reduced duration of drainage and seroma formation.

Keywords: Harmonic scalpel, Modified radical mastectomy, Unipolar cautery.

This is an Open Access article distributed under the terms of the Creative Commons Attribution License (http://creativecommons.org/licenses/by/4.0), which permits unrestricted use, distribution, and reproduction in any medium, provided the original work is properly cited.

\section{INTRODUCTION}

Breast carcinoma is awidespreadtumor and a major reason of carcinoma related mortality with $23 \%$ incidence of new cases and $14 \%$ of total deaths globally ${ }^{1}$. The incidence rate of breast cancer is highest in Pakistan among Asian countries with 51.7/100,000 as compare to GLOBOCAN incidence rate of 50.3/ $100,000^{2}$. The mortality rate of breast cancer for Pakistan (GLOBOCAN) was 25.2/100,000 highest among South Asian countries due to lack of awareness and delay clinical presentation ${ }^{3}$. There are two main types of breast carcinoma ductal and lobular classified into four stages, initial two confined to breast with axillary lymph node involvement while remaining two associated with chest wall fixity and metastases. Breast conservation operations (wide local excision, lumpectomy quadrantectomy) are for stage I patients while modified radical mastectomy (MRM) are for stage I \& II. A simple mastectomy removes the breast tissue, nipple, areola and skin but not all the lymph nodes. A modified radical mastectomy removes the entire breast - including the breast tissue, skin, areola and nipple - and most of the underarm (axillary) lymph

Correspondence: Dr Muhammad Ali Muazzam, Dept of Surgery, Combined Military Hospital Quetta Pakistan

Received: 17 Apr 2019; revised received: 12 Dec 2019; accepted: 24 Dec 2019 nodes ${ }^{4}$.

Simple surgical blades are traditionally used for breast surgery, however in the past two decades, electrocautery which performs its action via an electrical current that produces heat has replaced surgical blades, in terms of reduced blood loss and less operating time. However, the increased incidence of seroma formation is still a concern for many surgeons ${ }^{5}$.

With the advent of harmonic scalpel,a decade ago which uses ultrasound technology to create high-frequency mechanical vibrations to cut and coagulate at the same time, sealing vessels at lower temperatures than electro-surgery ${ }^{6-9}$, making a major breakthrough in the field of surgery; however, its use in modified radical mastectomy (MRM) is still limited which include cost and availability limitations ${ }^{10}$.

There are only a few studies comparing the harmonic scalpel and electrocautery in MRM, and they mainly compare intra operative parameters seroma formation with electrocautery and harmonic. Therefore, this study was done to determine if the harmonic scalpel offers any advantages in reducing postoperative seroma formation in patients under-going MRM when compared with electrocautery so that we can select the right method in MRM to reduce the post-operative complication in term of seroma formation in our general population. 


\section{METHODOLOGY}

This quasi experimental study was conducted in General Surgery department, Pak Emirates Military Hospital (PEMH) Rawalpindi, from July to December 2017. Sample size was calculated using Open Epi version 2.3 Software with the following assumptions \{confidence level $95 \%$, power $80 \%$, p1 $=8 \% 11-13$, and p2 $=33.3 \%{ }^{14}$, alpha $=5 \%$, (where p1 was expected proportion (seroma) in population 1 and p2 was the expected proportion (seroma) in population 2$\}$ sample size was 80.

After approval from Ethical Review Committee, a total of 80 female patients with Fine-needle aspiration cytology (FNAC)/biopsy-proven operable breast carcinoma (primary or post-neoadjuvant chemotherapy), female patients of all age groups, with tumour size $>4 \mathrm{~cm}$, patients who were not candidate for breast conservation surgery, positive margin after breast conservation surgery were included. Those whom didn't give consent, with ASA grade IIIand IV, history of previous breast surgeries, history of Diabetes, ulcers, discharge, or active wound infections in the breast or anywhere in the body and with inoperable advanced breast malignancy were excluded. The study also excluded patients with risk factors that could affect wound healing like on anticoagulant or corticosteroid therapy. We followed all provisions of the Declaration of Helsinki in this study.

All the eligible patients fulfilling inclusion criteria admitted through outpatient department (OPD) with informed consent, completing full workup for surgery and anaesthetic fitness.Diagnosis was confirmed by FNAC or trucut biopsy. Basic demographics data was noted like age, duration of complain and BMI.

Patients were assigned randomly into two groups, 40 sample size for harmonic scalpel group i.e. group A and 40 sample size for electrocautery group i.e. group B. Randomization was performed by Lottery method for both groups. The group assignments were using both harmonic and diathermy. Both the groups underwent standard modified radical mas-tectomy with lymph node dissection up to level III.

With negative pressure closed suction drainswere kept in both the groups, with one tube along the lower skin flap and another tube in axilla. In post-operative period, drain quantity was noted every $24 \mathrm{hr}$ for both groups. Postoperatively our criteria for drain removal was when drain quantity in the last 24 hours had fallen to $<30 \mathrm{ml}$. Development of seroma as a complication was defined when drain quantity continued to be $>40 \mathrm{ml}$ after postoperative day 7 or if there was clinically evident fluid collection beneath the skin flap during follow-up of patients after discharge from hospital. After removal of drain, we kept follow-up for the next 12 weeks, skin flaps were examined regularly to see any fluid collection noticing fluctuation, and seroma was confirmed with aspiration of fluid.

All patients were followed up on weekly basis and during each post-operative visit, the presence of seroma was assessed clinically, and the number of aspirations required for the seroma was also documented on especially designed proforma.

Data was analysed with IBM-SPSS-22. Comparison of proportion of group A and group B was done. Frequency and percentage weregenerated for qualitative variables such asseroma formation. Mean \pm SD was generated for quantitative variables like duration of complain, age, duration of procedure and BMI. Chisquare test was applied to compare seroma formation in both groups considering $p \leq 0.05$ as significant.

\section{RESULTS}

A total number of 80patients were included in study, of whom 40 patients (50\%) underwent MRM by harmonic scalpel and $40(50 \%)$ by electrocautery.

Mean age in group A and B was $51.36 \pm 11.04$ years vs $52 \pm 11.19$ years ( $p$-value 0.281 ). Mean duration of complain in group A and B was $1.675 \pm 0.47$

Table: Comparison of seroma formation \& drain parameters in both groups.

\begin{tabular}{c|l|c|c|c}
\hline $\begin{array}{l}\text { S. } \\
\text { No. }\end{array}$ & Parameters & $\begin{array}{c}\text { Group A } \\
\text { Harmonic Scalpel (n=40) }\end{array}$ & $\begin{array}{c}\text { Group B } \\
\text { Electrocautery (n=40) }\end{array}$ & $p$-value \\
\hline 1. & Mean drain days(days) & $6 \pm 2$ & $7 \pm 2.5$ & 0.001 \\
\hline 2. & Mean drain volume (ml) & $400 \pm 50$ & $600 \pm 55$ & 0.002 \\
\hline 3. & Seroma formation(patients) & $5(12.5 \%)$ & $10(25 \%)$ & 0.152 \\
\hline
\end{tabular}

put into sealed envelopes, which was opened when the women were admitted for procedure. All the patients had undergone MRM by a single classified surgical specialist having experience of atleast 8 months of months vs $1.775 \pm 0.42$ ( $p$-value 0.506$)$. Mean time of procedure in group A and B was $110.00 \pm 4.71$ mins vs $100.875 \pm 5.14$ ( $p$-value 0.307$)$. Mean BMI in group A and $B$ was $30.217 \pm 4.99 \mathrm{~kg} / \mathrm{m}^{2}$ vs $30.210 \pm 5.31 \mathrm{~kg} / \mathrm{m}^{2}$ 
( $p$-value 0.103). Seroma formation and drain parameters in both groups are compare in table.

\section{DISCUSSION}

Success of any surgery depend upon its safety, efficiency, complications, recurrences and acceptance from patient. Hence our study regarding the use of harmonic vs electrocautery for Post MRM outcomes has been discussed taking into account of these factors.

In this study, the mean age of patients was 51.68 years, which was in concordance with some earlier studies $^{13}$. The mean operative time in our study was longer using harmonic scalpel (110.00 \pm 4.71 vs 100.875 $\pm 5.14 \mathrm{~min} p>0.05)$. Our study showed seroma formation in $5(12.5 \%)$ patients in harmonic scalpel group as compare to $10(25 \%)$ patients in electrocautery group, $(p>0.05)$ results of our study are comparable with Damani et al who found in a study that frequency of seroma formation was $8 \%$ in harmonic scalpel ver-sus $20 \%$ in electrocautery $(p>0.05)$ in post modified radical mastectomy ${ }^{13}$. However difference was statis-tically non-significant.

Khan et al reported frequency of seroma formation was $21.3 \%$ in harmonic scalpel versus $33.3 \%$ in electrocautery $(p=0.071)$ in post modified radical mastectomy ${ }^{14}$.

Deo et al concluded also that use of harmonic scalpel $(16 \%)$ lower seroma formation as compare to cautery $(22 \%)^{9}$.

Galatius et al observed no significant difference among harmonic scalpel and electrocautery, [seroma formation in harmonic 50 (0-580) $\mathrm{ml}$ vs electrocautery $105(0-3775) \mathrm{ml}$ in aspects of surgery duration and complications including seroma ${ }^{15}$.

Researches by Kontos et al also exhibited positive outcomes of harmonic scalpel ${ }^{16}$.

Adwani et al observed similar encouraging outcomes supporting our observation ${ }^{11}$. Lumachi et al also showed benefits of harmonic scalpel over conventional scalpel ${ }^{17,18}$.

\section{CONCLUSION}

This study has concluded that frequency of seroma formation in harmonic scalpel is lower than electrocautery in post MRM, so it can be safely performed along with harmonic scalpel with reduced duration of drainage and seroma formation.

\section{CONFLICT OF INTEREST}

This study has no conflict of interest to be declared by any author.

\section{REFERENCES}

1. Siegel RL, Miller KD, Jemal A. Cancer statistics, 2016. CA Cancer J Clin 2016; 66(1): 7-30.

2. Bhurgri Y, Bhurgri A, Nishter S, Ahmed A, Usman A, Pervez S, et al. Pakistan - Country profile of cancer and cancer control 1995-2004. J Pak Med Assoc 2006; 56(1): 124-30.

3. GLOBOCAN. Fact sheets by Cancer-GLOBOCAN 2012.

4. Angahar LT. An overview of breast cancer epidemiology, risk factors, pathophysiology, and cancer risks reduction. MOJ Biol Med 2017; 1(4): 92-96.

5. Deo SV, Shukla NK. Modified radical mastectomy using harmonic scalpel. J Surg Oncol 2000; 74(1): 204-7.

6. Seki T, Hayashida T, Takahashi M, Jinno H, Kitagawa Y. A randomized controlled study comparing a vessel sealing system with the conventional technique in axillary lymph node dissection for primary breast cancer. Springer Plus 2016; 5(1): 1004.

7. AbulNagh G. Comparative study between using harmonic scalpel and electrocautery in modified radical mastectomy. J Surg Egypt 2007; 26: 176-80.

8. Harold KL, Pollinger H, Matthews BD, Kercher KW, Sing RF, Heniford BT. Comparison of ultrasonic energy, bipolar thermal energy, and vascular clips for the haemostasis of small, medium, large-sized arteries. Surg Endosc 2003; 17(8): 1228-30.

9. Deo SV, Shukla NK, Asthana S, Niranjan B, Srinivas G. A comparative study of modified radical mastectomy using harmonic scalpel and electrocautery. Singapore Med J 2002; 43(5): 226-28.

10. Galatius H, Okholm M, Hoffmann J. Mastectomy using ultrasonic dissection: effect on seroma formation. Breast 2003; 12(5): 338-41.

11. Adwani A, Ebbs SR. Ultracision reduces acute blood loss but not the seroma formation after mastectomy and axillary dissection: a pilot study. Int J Clin Pract 2006; 60(5): 562-64.

12. Currie A, Chong K, Davies GL, Cummins RS. Ultrasonic dissection versus electrocautery in mastectomy for breast cancer-a meta-analysis. Eur J Surg Oncol 2014; 38(1): 897-901.

13. Damani SR, Haider S, Shah SSH. Comparison of modified radical mastectomy using harmonic scalpel and electrocautery. J Surg Pak 2013; 18(1): 2-6.

14. Khan S, Khan S, Chawla T, Murtaza G. Harmonic scalpel versus electrocautery dissection in modified radical mastectomy: a randomized controlled trial. Ann Surg Oncol 2014; 21(3): 808-14.

15. Galatius H, Okholm M. Mastectomy using ultrasonic dissection: effect on seroma formation. Breast 2003; 12(1): 338-41.

16. Kontos M, Kothari A, Hamed H. Effect of harmonic scalpel on seroma formation following surgery for breast cancer: a prospective randomised study. J BUON 2008; 13(2): 223-30.

17. Lumachi F, Burelli P, Basso SM, Iacobone M, Ermani M. Usefulness of ultrasound scissors in reducing serous drainage after axillary dissection for breast cancer: a prospective randomized clinical study. Am J Surg 2014; 70(1): 80-104.

18. Lumachi F, Brandes AA, Burelli P, Basso SM, Iacobone M, Ermani M. Seroma prevention following axillary dissection in patients with breast cancer by using ultrasound scissors: a prospective clinical study. Eur J Surg Oncol 2004; 30(5): 526-30. 